\title{
Cognitive Health Progression Associated with Physical Exercise
}

\author{
Trevor Archer* \\ Department of Psychology, University of Gothenburg, Sweden
}

Submission: January 13,2018; Published: September 04, 2018

*Corresponding author: Trevor Archer, Department of Psychology, University of Gothenburg, Box 500, SE-430 50 Gothenburg, Sweden; Email: trevor.archer@psy.gu.se

\begin{abstract}
Sedentary life styles are associated with selectively and concerningly high incidences of health disruptions chronic disease states, such as cardiovascular disease, metabolic syndrome, sarcopenia, immune senescence, type 2 diabetes, cognitive decline, and cancer [1]. In this context, there is a plethora of evidence, that keeps increasing, positing the necessity of simultaneous exercise-training interventions, especially those applying multimodal exercise programs to ether with auxilliary tasks that regulated through sensory cues, have promote cognitive health remarkably well in both healthy older adults and clinically-effective, neurodegenerative patients, e.g. bearing Alzheimer's disease [2].
\end{abstract}

\section{Mini Review}

Although physicalfitness relates to improved cognition during later and older ages a comprehensive understanding concerning effects upon the different cognitive domains among patients diagnosed with dementia conditions is yet to be established. Thus, it is interesting to note that physical fitness and exercise was linked to a reduced level of cognitive deterioration expected with dementia, especially in executive functioning and provides empirical support for the cognitive benefits of interventions promoting PF for individuals with dementia [3]. Further, it was shown that a relatively straightforward 5-min bout of walking maintained at the individual's self-selected intensity was related to the enhancement of cognitive function, albeit among adults [4]. Mild cognitive impairment expresses the transitory stage between a normal level of cognitive ageing and full-fledged dementia thereby incorporating a critical time frame for the promotion of cognitive health through taylor-made intervention strategies, not least physical exercise. Among elderly individuals presenting early stages of Alzheimer's disease, aerobic exercise promoted cognitive functioning in that patients obtained specific benefits for instrumental activities of daily living $[5,6]$.

There are numerous instances of exercise multi-domain benefits, not least as illustrated by comparisons between lifestyles associated with regular exercise and others, less healthy, linked to sedentary behaviour. Physical exercise and sedentary behavior of older adults ( 55 years and above) dwelling in a Canadian (Montreal) community were estimated [7]; it was found that those individuals presenting probable mild cognitive impairment displayed lower physical exercise and higher sedentary behavior than those not presenting mild cognitive impairment whereas higher physical exercise and lower sedentary behavior were related to higher levels of the Alzheimer Disease Assessment Scale-Cognitive-Plus performance in those individuals not presenting mild cognitive impairment but not among those presenting probable mild cognitive impairment. Examining a population of high-risk stroke groups, complicated with hyper homocysteinemia, living in community (1196 cases), improved dietary control and lifestyle improvement with moderate increases in physical exercise were effective [8].

Results from populations of Chinese stroke patients have demonstrated that strength-resistance exercise promoted functionality, psychosocial aspects, and quality of life for poststroke patients whereas flexibility exercises ameliorated muscle spasticity problems, improved motor function, range of motion, and prevent contractures, and finally stretching exercises prevented joint contractures, muscle shortening, decrease spasticity, reduce joint stiffness and improve a post-stroke patient's overall function. Neuromuscular exercises can improve activities of daily living through the application of coordination and balance activities [9]. Finally, in a population of older adults presenting mild to moderate Alzheimer's disease aerobic exercise over six months maintained executive functioning as assessed using the Exit Interview-25, Behavioral Dys control Scale, and Golden Stroop tests [10]

An upsurge of findings from various domains of the behavioral sciences affirms that the engagement and commitment to a healthy lifestyle behavior, incorporating physical exercise programs, cognitive and social attendance, stress coping and curtailment, and resilience development, may both prevent and 
protect against the neuropsychiatric illnesses and disease states that accumulate during ageing and instead target the promotion of psychological and somatic health.

\section{References}

1. O'Donoghue G, Perchoux C, Mensah K, Lakerveld J, van der Ploeg H, et al. (2016) On behalf of the DEDIPAC consortium A systematic review of correlates of sedentary behaviour in adults aged 18-65 years: a socioecological approach. BMC Public Health16: 163.

2. Tait JL, Duckham RL, Milte CM, Main LC, Daly RM (2017) Influence of Sequential vs. Simultaneous Dual-Task Exercise Training on Cognitive Function in Older Adults. Front Aging Neurosci 9: 368.

3. Hollamby A, Davelaar EJ, Cadar D (2017) Increased Physical Fitness Is Associated with Higher Executive Functioning in People with Dementia. Front Public Health. 5: 346.

4. Jaffery A, Edwards MK, Loprinzi PD (2018) The Effects of Acute Exercise on Cognitive Function: Solomon Experimental Design. J Prim Prev 39(1): 37-46.

5. Vidoni ED, Perales J, Alshehri M, Giles AM, Siengsukon CF, et al. (2017) Aerobic Exercise Sustains Performance of Instrumental Activities of
Daily Living in Early-Stage Alzheimer Disease. J Geriatr Phys Ther doi: 10.1519/JPT.0000000000000172.

6. Bielak AAM, Mogle J, Sliwinski MJ (2017) What Did You Do Today? Variability in Daily Activities is Related to Variability in Daily Cognitive Performance. J Gerontol B Psychol Sci Soc Sci. doi: 10.1093/geronb/ gbx145.

7. Falck RS, Landry GJ, Best JR, Davis JC, Chiu BK, Liu-Ambrose T (2017) Cross-Sectional Relationships of Physical Activity and Sedentary Behavior With Cognitive Function in Older Adults With Probable Mild Cognitive Impairment. Phys Ther 97(10): 975-984.

8. Zhao NN, Zeng KX, Wang YL, Sheng PJ, Tang CZ, et al. (2017) Research on the nutrition and cognition of high-risk stroke groups in community and the relevant factors. Eur Rev Med Pharmacol Sci 21(23): 54085414.

9. Han P, Zhang W, Kang L, Ma Y, Fu L, et al. (2017) Clinical Evidence of Exercise Benefits for Stroke. AdvExp Med Biol 1000: 131-151.

10. Yu F, Vock DM, Barclay TR (2017) Executive function: Responses to aerobic exercise in Alzheimer's disease. Geriatr Nurs 39(2): 219-224.

Your next submission with Juniper Publishers will reach you the below assets

- Quality Editorial service

- Swift Peer Review

- Reprints availability

- E-prints Service

- Manuscript Podcast for convenient understanding

- Global attainment for your research

- Manuscript accessibility in different formats

( Pdf, E-pub, Full Text, Audio)

- Unceasing customer service

Track the below URL for one-step submission https://juniperpublishers.com/online-submission.php 